\title{
Enhanced antitumor efficacy of cisplatin in combination with HemoHIM in tumor-bearing mice
}

\author{
Hae-Ran Park ${ }^{1}$, Eun-Jin Ju' ${ }^{1}$, Sung-Kee Jo*1, Uhee Jung ${ }^{1}$, Sung-Ho Kim² and \\ Sung-Tae $\mathrm{Yee}^{3}$
}

\begin{abstract}
Address: ${ }^{1}$ Radiation Resarch Division for Bio-Technology, Advanced Radiation Technology Institute, Jeongeup Campus of Korea Atomic Energy Research Institute (KAERI), 1266 Sinjeong-dong Jeongeup-si Jeonbuk 580-185, Republic of Korea, ${ }^{2}$ College of Veterinary Medicine, Chonnam National University, Gwangju 500-757, Republic of Korea and ${ }^{3}$ Department of Biology, Sunchon National University, Sunchon 540-742, Republic of Korea

Email: Hae-Ran Park - hrpark@kaeri.re.kr; Eun-Jin Ju - eunjeen20@hanmail.net; Sung-Kee Jo* - skjo@kaeri.re.kr; Uhee Jung - uhjung@kaeri.re.kr; Sung-Ho Kim - shokim@chonnam.ac.kr; Sung-Tae Yee - sungtae@sunchon.ac.kr

* Corresponding author
\end{abstract}

Published: 17 March 2009

BMC Cancer 2009, 9:85 doi:10.1/86/147/-2407-9-85

This article is available from: http://www.biomedcentral.com/I47/-2407/9/85

(C) 2009 Park et al; licensee BioMed Central Ltd.

This is an Open Access article distributed under the terms of the Creative Commons Attribution License (http://creativecommons.org/licenses/by/2.0), which permits unrestricted use, distribution, and reproduction in any medium, provided the original work is properly cited.
Received: 23 July 2008
Accepted: 17 March 2009

\begin{abstract}
Background: Although cisplatin is one of the most effective chemotherapeutic agents, cisplatin alone does not achieve a satisfactory therapeutic outcome. Also cisplatin accumulation shows toxicity to normal tissues. In this study, we examined the possibility of HemoHIM both to enhance anticancer effect with cisplatin and to reduce the side effects of cisplatin in melanoma-bearing mice.

Methods: HemoHIM was prepared by adding the ethanol-insoluble fraction to the total water extract of a mixture of 3 edible herbs, Angelica Radix, Cnidium Rhizoma and Paeonia Radix. Anticancer effects of HemoHIM with cisplatin were evaluated in melanoma-bearing mice. We used a $\mathrm{Cr}^{51}$-release assay to measure the activity of NK/Tc cell and ELISA to evaluate the production of cytokines.
\end{abstract}

Results: In melanoma-bearing mice, cisplatin $(4 \mathrm{mg} / \mathrm{kg} \mathrm{B.W}$.) reduced the size and weight of the solid tumors, and HemoHIM supplementation with cisplatin enhanced the decrease of both the tumor size $(p<0.1)$ and weight $(p<0.1)$. HemoHIM itself did not inhibit melanoma cell growth in vitro, and did not disturb the effects of cisplatin in vitro. However HemoHIM administration enhanced both NK cell and Tc cell activity in mice. Interestingly, HemoHIM increased the proportion of NK cells in the spleen. In melanoma-bearing mice treated with cisplatin, HemoHIM administration also increased the activity of NK cells and Tc cells and the IL-2 and IFN- $\gamma$ secretion from splenocytes, which seemed to contribute to the enhanced efficacy of cisplatin by HemoHIM. Also, HemoHIM reduced nephrotoxicity as seen by tubular cell of kidney destruction.

Conclusion: HemoHIM may be a beneficial supplement during cisplatin chemotherapy for enhancing the anti-tumor efficacy and reducing the toxicity of cisplatin. 


\section{Background}

Chemotherapy has been one of the major therapeutic modalities commonly used for the treatment for a variety of cancer patients. However, in many cases, chemotherapy or radiotherapy alone cannot achieve a satisfactory therapeutic outcome, namely the complete remission of tumors, and induces severe side effects at therapeutically effective doses.

Cisplatin (cis-diaminedichloroplatinum (II) or CDDP), a platinum-containing anticancer drug, is one of the most commonly used cytotoxic agents for the treatment of a variety of solid malignant tumors. Despite its excellent anticancer activity, the clinical use of cisplatin is often limited by its undesirable side effects, such as severe nephrotoxicity and hepatotoxicity [1,2]. Although the precise mechanism for the cisplatin-induced toxicity is not well understood, cisplatin is preferentially taken up and accumulated in the liver and kidney cells [3], resulting in the enhanced production of reactive oxygen species (ROS) and the decrease in antioxidant enzymes [4-7]. Therefore, antioxidants have been administered before cisplatin treatment to protect against nephrotoxicity [8-10].

Complementary and alternative medicine defined by the National Center as a group of diverse medical and health care systems is not normally considered to be conventional medicine [11]. Complementary and alternative medicine does not inhibit tumor growth. These treatments might be undertaken adjuvant to, or instead of, conventional treatments. Numerous herbal medical products are promoted as complementary and alternative medicines. In addition, scientific and medical studies in Korea, China, and Japan, and more recently in the United States, have increasingly shown that plant-derived polysaccharides have potent immunotherapeutic properties with respect to the prevention and treatment of cancer [12-19].

A new herbal composition, HemoHIM, was designed by adding its polysaccharide fraction into a hot water extract of an herb mixture consisting of Angelica Radix, Cnidium Rhizoma and Paeonia Radix. This composition was designed to protect the self-renewal tissues and to promote a recovery of the immune system against oxidative stresses, such as irradiation $[20,21]$. The general composition of HemoHIM were $60.4 \%$ carbohydrate, $6 \%$ protein and $33.6 \%$ other (Data not shown). The immune modulating components in HemoHIM were the ethanol-insoluble fraction [21], and the polysaccharide content in this fraction was $40.9 \%( \pm 3.8)$ (Data not shown). In addition, the functional components included in the ethanol-soluble fraction of HemoHIM were Gallic acid $[0.2 \%( \pm$ $0.06)]$, chlorogenic acid $[0.33 \%( \pm 0.05)]$, paeoniflorin $[1.32 \%( \pm 0.15)]$, nodakenin $[0.58 \%( \pm 0.04)]$ and ben- zoic acid $[0.17 \%( \pm 0.05)]$ (Data not shown). Especially, these 3 herbs are listed as raw materials in the Korea Food Code. Finally, HemoHIM has been proven to be safe for long-term administration (data not shown).

Surveillance capacity to tumor cells was mediated nonspecifically by dendritic cells, macrophages and natural killer cells and was mediated specifically by $\mathrm{T}$ cells including cytotoxic T (Tc) cells. Both $\mathrm{T}$ and NK cells have been shown to be anticancer effector cells [22,23]. Also, IFN- $\gamma$ and IL-2 have been shown to have anticancer activity in animals [24,25].

In this study, the possibility of HemoHIM increasing the immune surveillance capacity to tumor cells through both NK cells and Tc cells in melanoma-bearing mice treated with cisplatin was assessed. Also, we examined its protective effect against cisplatin-induced nephrotoxicity in melanoma-bearing mice. Our results suggest that HemoHIM may be a beneficial supplement during cisplatin chemotherapy by enhancing the anti-tumor efficacy and reducing the toxicity of cisplatin.

\section{Methods \\ Animals}

Research was approved and conducted according to the principles enunciated in the 'Animal Care Act', prepared by the Ministry of Agriculture and Forestry, Republic of Korea. 8-week-old female C57BL/6 (H-2 $\left.{ }^{\mathrm{b}}\right)$ mice were used (The Orient Inc.; Charles River Technology; Seoul, Korea). The mice were housed in polycarbonate cages under a specific pathogen-free condition, and were fed with a standard animal diet and water ad libitum.

\section{Preparation of HemoHIM}

A mixture of 3 edible medicinal herbs, Angelica Radix (root of Angelica gigas Nakai), Cnidii Rhizoma (rhizome of Cnidium officinale Makino), and Paeonia Radix (root of Paeonia japonica Miyabe), was decocted for 4 hours in boiling water to obtain a total extract (HIM-I). One half of HIM-I was fractionated into an ethanol-soluble fraction and into an ethanol-insoluble polysaccharide fraction by a precipitation in $80 \%$ ethanol. HemoHIM was prepared by adding the ethanol-insoluble polysaccharide fraction to the other half of HIM-I.

\section{Cell culture}

B16F0 (Melanoma cell line; CRL-6322) and YAC-1 (Molony virus induced leukemia; TIB-160) were purchased from ATCC (Rockville, MD, USA) and cultured in RPMI 1640 supplemented with 10\% fetal bovine serum (FBS, GIBCO BRL, Grand Island, USA)), $2 \times 10^{-2} \mathrm{M}$ HEPES buffer, $2 \times 10^{-}$ ${ }^{3} \mathrm{M}$ L-glutamine, $100 \mathrm{U} / \mathrm{ml}$ penicillin and $50 \mu \mathrm{g} / \mathrm{ml}$ streptomycin (GIBCO BRL). All cells were grown at $37^{\circ} \mathrm{C}$ in a humidified atmosphere containing $5 \% \mathrm{CO}_{2}$. 


\section{Cisplatin injection and HemoHIM administration in tumor-bearing mice model}

Mice were divided randomly into three groups (Control, Cisplatin and Cisplatin+HemoHIM), and each group consisted of twenty mice. B16F0 melanoma (5 × $10^{5}$ cells/ mouse) was inoculated into subcutaneous femoral left region of mice at 3 days before an initial injection of cisplatin. Cisplatin was injected intraperitoneally at $4 \mathrm{mg} / \mathrm{kg}$ body weight (B.W.) on day 0, 7 and 14 (total three injections). Experimental group was intubated with HemoHIM at a final concentration of $100 \mathrm{mg} / \mathrm{kgB} . \mathrm{W}$. by everyday from day -1 to day 16 , while the control group received only water. The scheme of the administration procedure is summarized in Fig. 1. On day 17 after initial injection of cisplatin, all mice of each group were experimented, respectively, to evaluate tumor weight or tumor size. The tumor size was calculated as follows: tumor size $=\mathrm{ab}^{2} / 2$, where $\mathrm{a}$ and $\mathrm{b}$ are the larger and smaller diameters, respectively.

\section{Melanoma cell growth assay in vitro}

The effect of cisplatin and HemoHIM on the number of viable melanoma cells was assessed by CCK-8 (WST-8; Dojindo Lab, Kumamoto, Japan). The principle underlying the cell viability assessment by CCK- 8 is based on the dehydrogenase activity detection in viable cells, similar with the principle of MTT. Briefly, the melanoma cells were seeded on to 96-well plates at a density of $7 \times 10^{3}$ cells per well in $100 \mu \mathrm{l}$ of media. After incubation for 24 hours, cells were treated with various concentration of cisplatin and with HemoHIM $100 \mu \mathrm{g} / \mathrm{ml}$ for 24 hours. After incubation, a CCK- 8 solution was added to each well. Cells were incubated at $37^{\circ} \mathrm{C}$ for two hours and the optical density was measured using microplate reader (Molecular Devices) at $450 \mathrm{~nm}$ (-Ref. $570 \mathrm{~nm}$ ).

\section{Preparation of lymphocyte in the spleen}

Spleens were removed aseptically from the mice and a single cell suspension was prepared by mincing the spleen. The spleen lymphocytes were prepared by a density gradient centrifugation on a Ficoll-Hypaque solution (SigmaAldrich Co., St. Louis, MO, USA). All the cell suspensions were maintained in the RPMI 1640 media supplemented with $10 \%$ fetal bovine serum (FBS), $2 \times 10^{-2} \mathrm{M}$ HEPES buffer, $2 \times 10^{-3} \mathrm{M}$ L-glutamine, $1 \times 10^{-3} \mathrm{M}$ pyruvate, 100 $\mathrm{U} / \mathrm{ml}$ penicillin, $50 \mu \mathrm{g} / \mathrm{ml}$ streptomycin, $5 \times 10^{-5} \mathrm{M}$ of $2-$ mercaptoethanol and $1 \%$ nonessential amino acid. All the supplements were purchased from GIBCO BRL (Grand Island, USA).

\section{HemoHIM administration in MMC-treated tumor-bearing mice model}

Firstly, harvested B16F0 melanoma was inactivated by mitomicin $\mathrm{C}(\mathrm{MMC})$ treatment $(50 \mu \mathrm{g} / \mathrm{ml}$, incubation for 40 minutes at $37^{\circ} \mathrm{C}$ water bath). MMC-treated B16F0 melanoma were inoculated intraperitoneally with $1 \times 10^{6}$ cells/mouse 3 days after an initial administration of HemoHIM. Experimental group was intubated with HemoHIM at a final concentration of $100 \mathrm{mg} / \mathrm{kgB}$.W. by everyday from day -3 to day 4 , while the control group was received only water. Ten days after cancer cell inoculation, spleen lymphocytes were prepared as effector cells to measure the activity of NK cells and Tc cells through $\mathrm{Cr}^{51}$ release assay.

\section{Assay for NK cell and cytotoxic T (Tc) cell mediated cancer cell killing activity}

YAC-1 tumor targets or B16F0 tumor targets were labeled with ${ }^{51} \mathrm{Cr}$-sodium chromate (Amersham Pharmacia Biotech, Kangnam-ku, Seoul, Korea) at a dose of $40 \mu \mathrm{Ci} / 10^{6}$ cells for $60 \mathrm{~min}$ to measured NK cell activity or Tc cell activity, respectively. The cells were washed three times in HBSS (Hank's

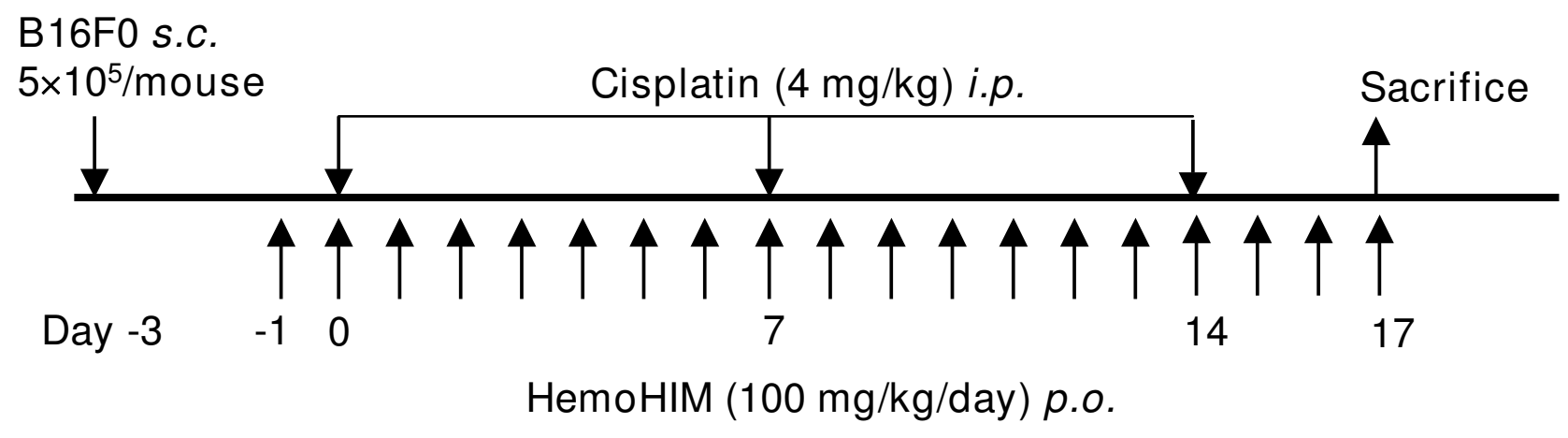

Figure I

The experimental schedule used for assessing the efficacy of HemoHIM in melanoma-bearing mice which were injected with cisplatin. BI6F0 melanoma cells $(5 \times 105 /$ mouse) were inoculated into subcutaneous femoral left region of mice 3 days before an initial injection of cisplatin. Cisplatin was intraperitoneally injected at $4 \mathrm{mg} / \mathrm{kg}$ B.W., and HemoHIM was daily given at $100 \mathrm{mg} / \mathrm{kg}$ B.W. from day $-\mathrm{I}$ to day 16 . On day 17 after initial injection of cisplatin, all mice of each group were experimented, respectively, to evaluate various parameters. 
A

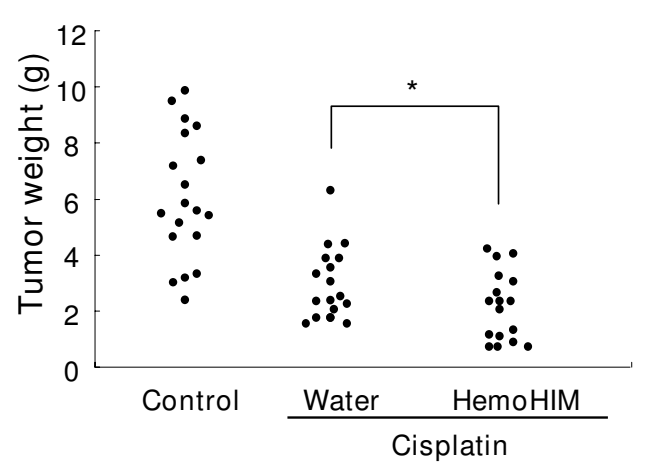

C
B

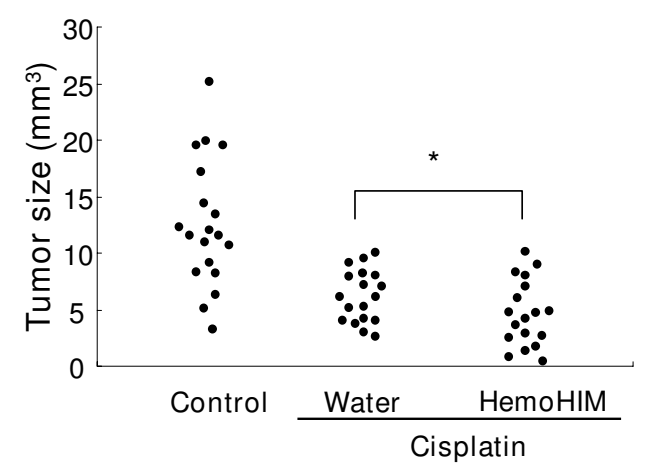

Control
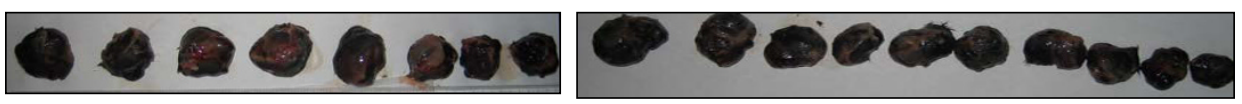

\begin{tabular}{l|l|l|} 
Water & & \\
Cisplatin & \\
HemoHIM &
\end{tabular}

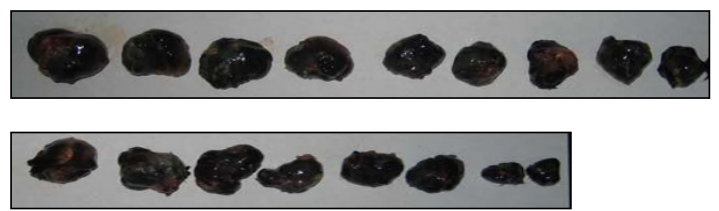

Figure 2

The inhibition of tumor growth was enhanced by HemoHIM administration in melanoma-bearing mice which were injected with cisplatin. All mice performed as described in figure 3 were sacrificed at 17 days after initial injection of cisplatin. Tumor weight (A) and size (B) were measured. (C) Photographs of melanoma solid tumor taken from all mice of each group. There were twenty mice in each group. Data show the Mean \pm SD. $*_{p}<0.1$ compared with only cisplatin treated group.

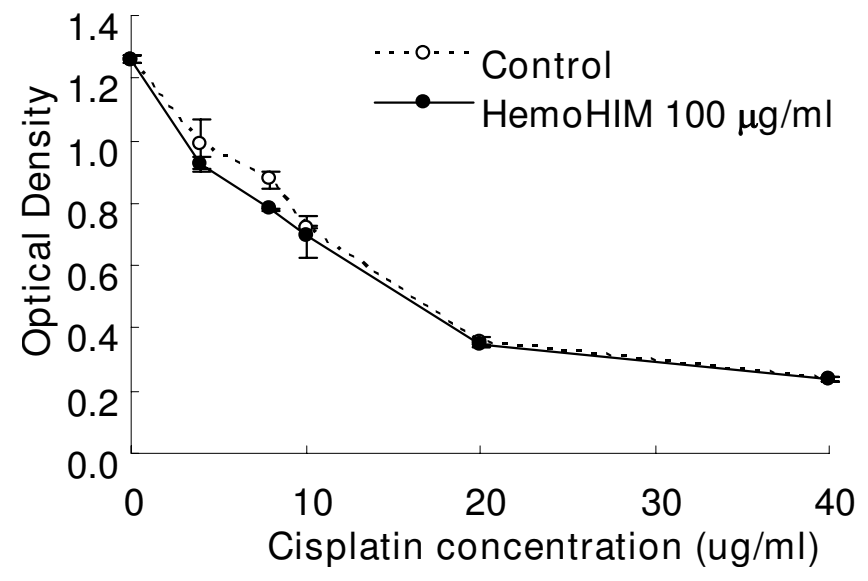

Figure 3

Growth inhibition effect of cisplatin and HemoHIM on melanoma cells in vitro. The melanoma cells were seeded at a density of $7 \times 10^{3}$ cells per well. After incubation for 24 hours, cells were treated with various concentration of cisplatin and with HemoHIM $100 \mu \mathrm{g} / \mathrm{ml}$ for 24 hours. After incubation, a CCK-8 solution was added to each well for I hour and then the optical density was measured.
Balanced Salt Solution; Sigma-Aldrich Co.) and resuspended to a final concentration of $2 \times 10^{5}$ cells $/ \mathrm{ml}$. Twenty thousand target cells and $10^{6}$ or $2 \times 10^{6}$ spleen effector cells were plated into the wells of a 96-well $\mathrm{U}$ bottom plate. The plates were then incubated at $37^{\circ} \mathrm{C}$ for $4 \mathrm{hr}$ in humidified air containing $5 \% \mathrm{CO}_{2}$. Following a centrifugation at $350 \mathrm{~g}$ for $10 \mathrm{~min}, 100$ $\mu \mathrm{l}$ of the supernatant was harvested from each well and counted for $1 \mathrm{~min}$ in a gamma counter (Wallac, Wellesley, MA, USA). The percent lysis was calculated as follows: \% lysis $=\{[\mathrm{CPM}$ (experimental) - CPM (spontaneous) $] /[\mathrm{CPM}$ (maximum) - CPM (sponstaneous)] $\} \times 100$.

\section{Flow cytometry analysis of NK and Tc cells in spleen lymphocytes}

The spleen lymphocytes were stained with fluorescentlabeled antibodies or isotype control antibodies in phosphate buffered saline (PBS). After staining for 30 minutes, the lymphocytes were washed three times with a fresh FACS media and then analyzed by flow cytometry (Backman Coulter, Miami, Florida, USA). A fluorescence histogram of at least 50,000 counts was analyzed in each sample. The following reagents from $\mathrm{BD}$ PharMingen 
(San Diego, CA, USA) were used: PE-conjugated antiNK1.1 and FITC-conjugated anti-CD8.

\section{Condition for a cytokine production in vitro}

The spleen lymphocytes $\left(2 \times 10^{6}\right.$ cells/well $)$ obtained from the mice were stimulated with concanavalin A (ConA) at $1 \mu \mathrm{g} / \mathrm{ml}$ for 1 or 2 days to measure IL-2 and IFN- $\gamma$ level in supernatant.

\section{Antibodies and the enzyme-linked immunosorbent assay (ELISA)}

For the IL-2, clone JES6-1A12 was used as the capture Ab, and biotin-labelled JES6-5H4 was the detecting Ab. For the IFN- $\gamma$ measurements, clone R4-6A2 was used as the capture Ab, and biotin-labeled XMG1.2 was the detecting $\mathrm{Ab}$. All the antibodies as well as the recombinant IFN- $\gamma$ and IL-2 were purchased from BD PharMingen (San Diego, CA, USA). Cytokines were determined by previously described ELISA method [26].

\section{Histopathological examination of kidney by hematoxylin and eosin staining}

Kidney from mice of each group on day 17 after initial injection of cisplatin was removed and fixed in $10 \%$ buffered formalin for 2 days. The paraffin-embedded sections (5 $\mu \mathrm{m}$ thick) were stained with hematoxylin and eosin (H\&E) for histolpathological examination and observed under light microscope at $\times 200$ magnifications.

\section{Statistical analysis}

Data were expressed as mean \pm S.D. and a statistical significance was analyzed by using a Student's $t$-test. Differences with a $p$ value of less than 0.05 were taken as significant, and considerable with a $p$ value of less than 0.1 .

\section{Results \\ HemoHIM enhances the antitumor efficacy of cisplatin in tumor-bearing mice}

To assess the effect of HemoHIM on tumor growth inhibition in cisplatin treated B16F0 melanoma-bearing mice, we used a tumor-bearing mice model that was summarized in Fig. 1. As shown in Fig. 2A and 2B, at 20 days after melanoma inoculation, the tumor weight and size of the control group without cisplatin and HemoHIM treatment were $6.093 \mathrm{~g}( \pm 2.28)$ and $12.6 \mathrm{~mm}^{3}( \pm 5.65)$, respectively. However, in the cisplatin-injected group, tumor weight $(2.97 \mathrm{~g}( \pm 1.29))$ and size $\left(6.3 \mathrm{~mm}^{3}( \pm 2.32)\right)$ were reduced significantly in comparison to the control group. HemoHIM supplementation with cisplatin resulted in a further reduction in both the tumor weight $(2.22 \mathrm{~g}( \pm$ $1.24)$ ) and size $\left(4.7 \mathrm{~mm}^{3}( \pm 2.93)\right)$. Only HemoHIM supplementation without cisplatin showed no reduction in tumor weight $[6.15 \mathrm{~g}( \pm 1.238)]$ when compared with the control group (Data not shown). This suggests that HemoHIM itself did not show a reduction effect of tumor growth. Photographs are shown in Fig. 2C.

\section{HemoHIM enhances the activity of NK and Tc cells rather than directly killing cancer cells}

The anticancer effect of cisplatin mainly depends on its DNA-damaging activity, via its direct interaction with DNA to form DNA adducts [27]. As shown in Fig. 3, cisplatin inhibited melanoma cell growth in a dose-dependent manner, with $\mathrm{IC}_{50}$ at about $15 \mu \mathrm{g} / \mathrm{ml}$. However, HemoHIM itself did not inhibit melanoma growth in vitro (Data not shown), nor did it disturb the working of cisplatin in vitro (Fig. 3).

Because HemoHIM did not directly kill cancer cells, we thought that the activity of immune cells which were in charge of tumor surveillance may be enhanced by HemoHIM. We investigated the cancer cell-killing activity of NK and Tc cells, as they are in charge of innate and adaptive immunity against tumor, respectively. To investigate the activity of Tc cell, we used the mice which were immunized with mitomycin $\mathrm{C}(\mathrm{MMC})$-treated melanoma cells. As shown in Fig. 4A and 4B, HemoHIM administration enhanced cancer cell-killing activity of NK cells and Tc cells in MMC-treated melanoma cell-bearing mice ( $\mathrm{p}<$ 0.05 and $\mathrm{p}=0.06$, respectively). Also, the proportion of NK cell in spleen lymphocytes was increased by HemoHIM administration ( $\mathrm{p}<0.05$ ), but not the proportion of Tc cells. Specially, these results were important because NK cells take part in both innate and adaptive immunity, and are regarded as interfaces between the innate and adaptive immune systems [28].

\section{The enhanced efficacy of cisplatin with HemoHIM in} melanoma-bearing mice was due to increasing IL-2 and IFN$\gamma$ secretion and enhancing the activity of NK and Tc cells As the mechanisms for an enhanced anticancer efficacy of cisplatin in combination with HemoHIM in melanoma cell-bearing mice (Fig. 1), we concentrated on the activity of NK and Tc cells because these cells play an important role on cancer surveillance. As shown Fig. 5A and 5B, cisplatin injection alone in melanoma-bearing mice did not enhance or decrease the activity of NK cells and Tc cells. However, HemoHIM administration enhanced the activity of NK cells in melanoma-bearing mice which were treated with cisplatin ( $\mathrm{p}=0.1$; Fig. $5 \mathrm{~A}$ ). In addition, the activity of Tc cells was enhanced significantly by HemoHIM administration ( $\mathrm{p}<0.05$; Fig. 5B). These data suggested that the enhanced anticancer efficacy of cisplatin in combination with HemoHIM administration was due to the increase in the activity of NK and Tc cells that are in charge of tumor surveillance.

Macrophages, dendritic cells, NK cells and Tc cells that are able to recognize, bind and subsequently kill tumor cells, were activated by cytokines such as IL- 2 and IFN- $\gamma$. In our previous study, lymphocytes treated with HemoHIM alone enhanced the expression of IL- 2 and IFN- $\gamma$ in vitro (data not shown). Truly, IL-2 and IFN- $\gamma$ are potent activa- 
A

\section{NK cell activity}
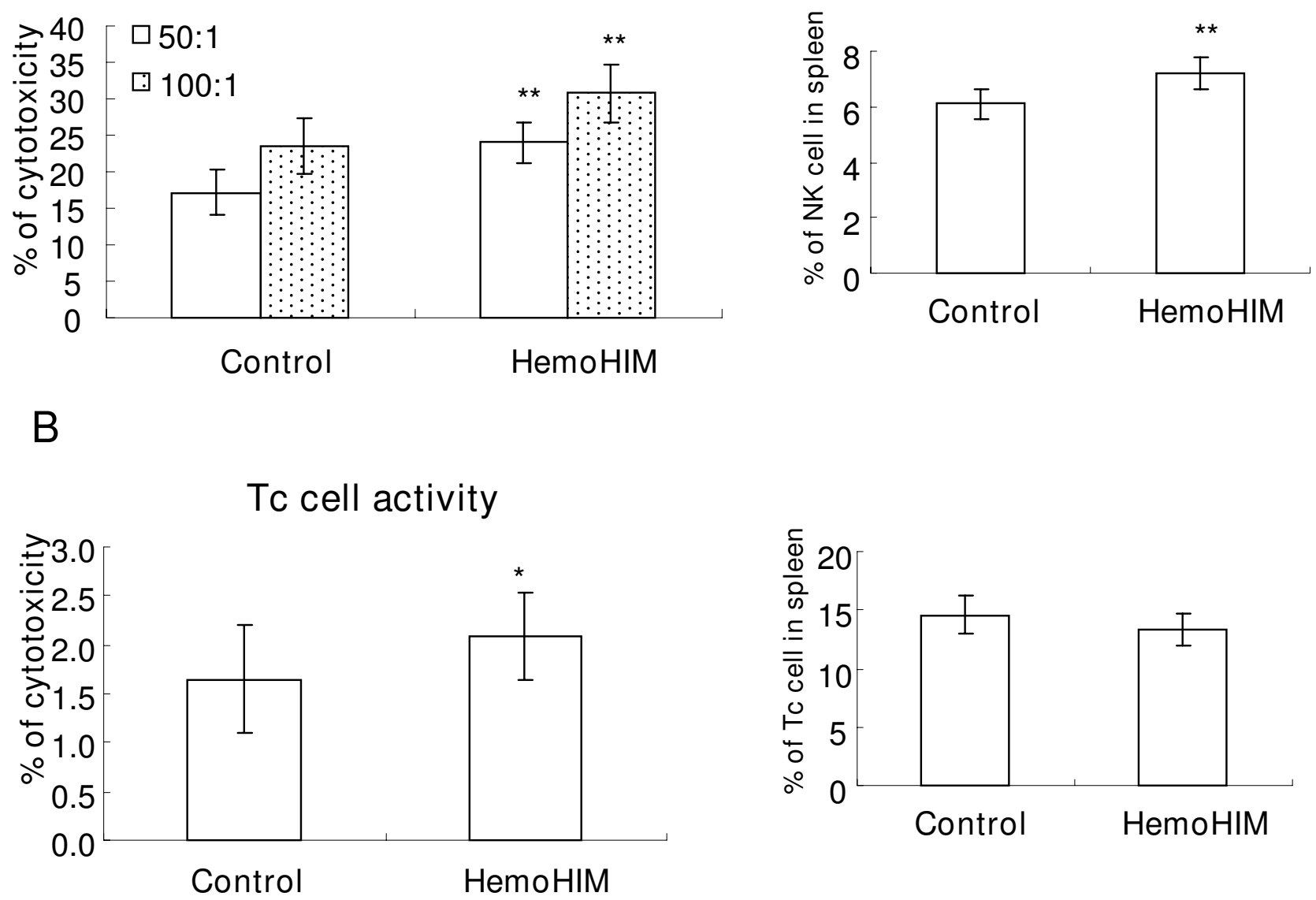

\section{Figure 4}

Effect of HemoHIM on cancer cell killing activity of NK cells and Tc cells. C57BL/6 mice were orally administrated with HemoHIM (I00 mg/kg B.W.) and injected with MMC-treated BI6FO melanoma (I × $10^{6}$ cell/mouse) into peritoneal cavity. 10 days after cancer cell inoculation, the cancer cell killing activity of $\mathrm{NK}$ cells or $\mathrm{Tc}$ cells was determined by ${ }^{51} \mathrm{Cr}$ release assay as described in Materials and Methods. There were six mice in each group. Data show the Mean \pm SD. $* p=0.06$ and $* * p<0.05$ compared with mice administrated water.

tors of NK cell and Tc cell effector functions. We therefore ascertained whether HemoHIM administration enhanced the production of IL- 2 and IFN- $\gamma$ in melanoma-bearing mice treated with cisplatin. HemoHIM administration significantly enhanced IL-2 ( $<<0.001$; Fig. 5C) and IFN- $\gamma$ (p $<0.05$; Fig. 5D) production in melanoma-bearing mice treated with cisplatin.

\section{HemoHIM decreases the cisplatin-induced nephrotoxicity} in tumor-bearing mice

Undesirable side effects of cisplatin appear in the kidney and liver, due to cisplatin accumulation in these organs [3]. As one of the mechanisms for cisplatin-induced toxicity is the enhanced production of ROS in these organs, we thought that HemoHIM may have a radical scavenging activity $[20,21]$, reducing cisplatin-induced damage.
Experimental studies in animals have shown that a minimum dose of cisplatin $(5 \mathrm{mg} / \mathrm{kg}$ body weight, i.p.) was sufficient to induce nephrotoxicity in rats $[29,30]$. In this study, the cisplatin was injected at $4 \mathrm{mg} / \mathrm{kg}$ body weight three times once weekly. The nephrotoxicity was assessed using kidneys removed from mice on day 17 after an initial injection of cisplatin, and the representative result of each group is shown in Fig. 6. In the histopathological examination of the kidney, cisplatin destroyed renal tubular cells (Fig. 6). However HemoHIM administration reduced the destruction of renal tubular cells by cisplatin.

\section{Discussion}

HemoHIM is an herbal composition designed to protect the self-renewal tissues and to promote the recovery of the immune system against an oxidative stresses such as an 

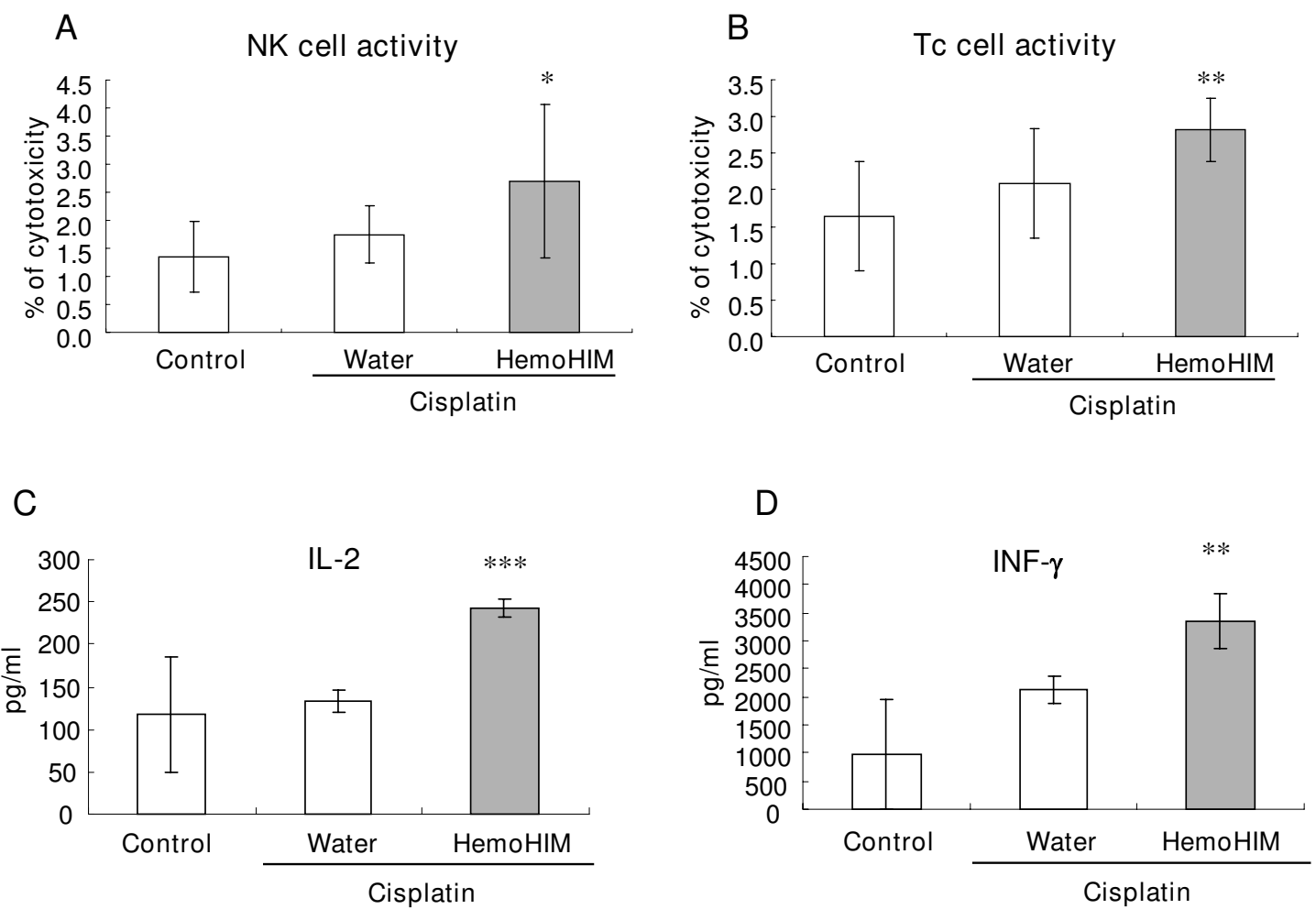

\section{Figure 5}

HemoHIM administration promotes immune responses for tumor surveillance in melanoma-bearing mice which were injected with cisplatin. All mice performed as described in figure 3 were sacrificed at 17 days after initial injection of cisplatin. (A)(B) The cancer cell killing activity of NK cells or Tc cells was determined by ${ }^{51} \mathrm{Cr}$ release assay as described in Materials and Methods. (C)(D) Spleen lymphocytes were cultured with ConA (I $\mu \mathrm{g} / \mathrm{ml})$. After I or 2 days, IL-2 and IFN- $\gamma$ in culture supernatants were measured by ELISA as described in Materials and Methods. There were twenty one mice in each group. The spleens of three mice were pooled. Bars show the means \pm SD of the septuple experiments. $* p=0 . I, * * p<$ 0.05 and $* * * p<0.001$ compared with only cisplatin treated group.

irradiation. In this study, we examined the possibility of HemoHIM both to enhance the anticancer effect of cisplatin and to reduce its side effects in melanoma-bearing mice. In our previous studies, HemoHIM was tested for its efficacy as a radioprotective agent $[20,21]$. Also, we investigated the effect of HemoHIM on a restoration of the immune functions which had been impaired in aged mice [31]. Besides, in our previous study, we showed that HemoHIM accelerated the recovery of immune cells in mice treated with cyclophosphamide, which is a wellknown anticancer agent [32]. In this study, unlike cisplatin, HemoHIM alone did not directly kill the cancer cells. Nevertheless, our results showed that HemoHIM administration enhanced antitumor efficacy of cisplatin in melanoma-bearing mice.

Immune responses that are capable of killing tumor cells consist of dendritic cells, macrophages, NK cells and Tc cells. Tc cells may perform a surveillance function by rec- ognizing and killing potentially malignant cells that express peptides derived from mutant cellular proteins or oncogenic viral proteins and presented in association with class I MHC molecules. NK cells kill many types of tumor cells, especially cells that have reduced class I MHC expression and can escape killing by Tc cells [33]. In vitro studies using cells from humans and several other mammalian species, as well as in vivo studies in mice and rats, have long suggested that tumor cells are recognized as NK cell targets [34]. Also, NK cells act as regulatory cells to influence various other cell types, such as dendritic cells, helper T (Th) cells, Tc cells and B cells [35]. Many studies for immuno-cancer therapy were focused on enhancing the activity of NK cells as well as Tc cells against tumor cells. In our data, cisplatin alone decreased tumor size, but did not enhance the activity of NK cells and Tc cells (Fig. 5). Also, HemoHIM alone without cisplatin did not enhance the activity of these cells (data not shown). However, HemoHIM administration with cisplatin injection 


\section{Cisplatin ( $4 \mathrm{mg} / \mathrm{kg}$ body weight $\times 3$ times)}
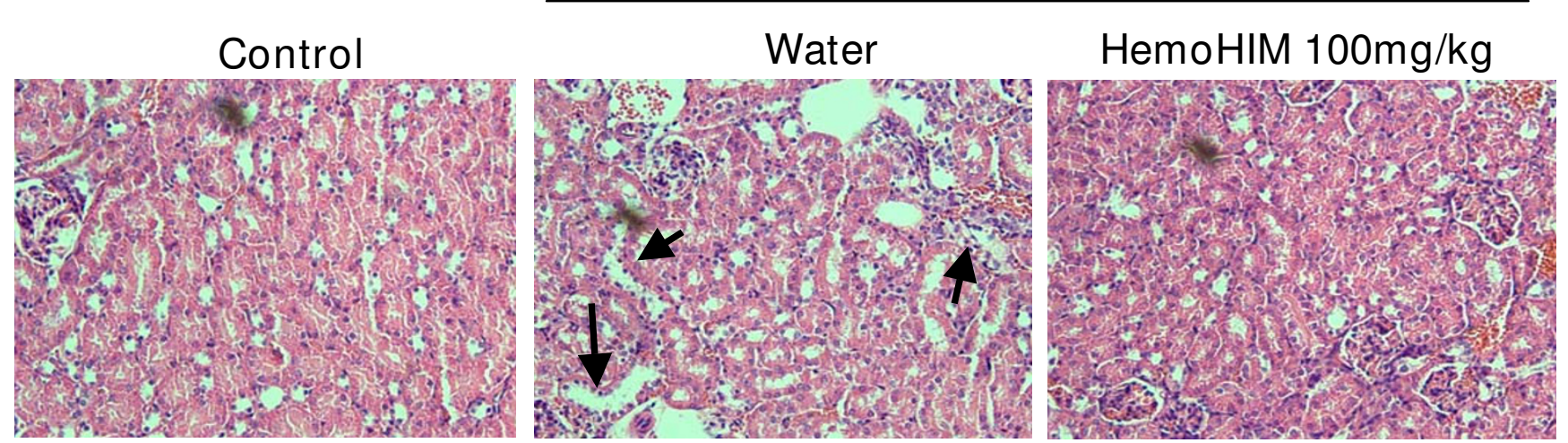

\section{Figure 6}

HemoHIM reduces the cisplatin-induce damage of kidney. Kidney from mice of each group on day 17 after initial injection of cisplatin was removed and fixed in 10\% buffered formalin for 2 days. The paraffin-embedded sections ( $5 \mu \mathrm{m}$ thick) were stained with hematoxylin and eosin (H\&E) for histolpathological examination and observed under light microscope at $\times 200$ magnifications. The result shown here is representative cortex from each group. (A) Control, cortex $(\times 200)$, (B) Cisplatin control, cortex (× 200), renal tubule cell destruction (marked by arrows), (C) Cisplatin+HemoHIM, cortex (× 200).

increases the activity of $\mathrm{NK}$ cells and Tc cells in melanoma-bearing mice (Fig. 5A and 5B), while the tumor size was decreased by cisplatin. Thus, we suggest that the mechanism of action of cisplatin and HemoHIM in tumor-bearing mice differ.

IL-2 and IFN- $\gamma$ are potent activators of NK cell and Tc cell effecter functions. For these reasons, cytokine therapies of malignant tumors using IL-2, IL-12, and IFN- $\gamma$ have been investigated extensively in experimental and clinical studies [34]. It is also well known that IL-2 and IFN- $\gamma$ promote tumor-reactive lymphocyte proliferation, cytotoxicity and, to some extent, cytokine secretion [36-41]. IFN- $\gamma$ is a pleiotropic immunoregulatory cytokine that has been used for clinical treatment of certain tumors $[42,43]$. However, the clinical application of such cytokines has been hampered largely due to their undesirable side effects $[44,45]$. In our data, HemoHIM administration with cisplatin injection increased the secretion of IL-2 and IFN- $\gamma$ in melanoma-bearing mice.

Although cisplatin is an anticancer drug highly effective against several cancers, cisplatin is toxic to liver and kidney cells through producing ROS $[1-4,30]$. However, many studies to counter nephrotoxicity through the administration of antioxidants have been performed [810]. As HemoHIM was designed to protect the selfrenewal tissues and to promote a recovery of the immune system against oxidative stresses $[20,21]$, we thought it may be able to decrease cisplatin-induced kidney damage. As expected, HemoHIM administration reduced nephrotoxicity as seen by tubular cell destruction of kidney.
Based on the overall these results, the possibility of HemoHIM both to enhance anticancer effect of cisplatin and to reduce its side effects in melanoma-bearing mice were ascertained. However, the protective efficacy of HemoHIM on cisplatin-induce damage in the kidney needs to be investigated further.

\section{Conclusion}

In conclusion, although the manner in which HemoHIM administration decreases cisplatin-induced kidney damage remains unknown, our results indicate that HemoHIM may be a useful complementary agent during cisplatin chemotherapy by enhancing the anti-tumor efficacy and reducing the toxicity of cisplatin.

\section{Competing interests}

The authors declare that they have no competing interests.

\section{Authors' contributions}

HRP carried out making HemoHIM, the cell culture, $\mathrm{Cr}^{51}$ relaeas assay, animal experiments, and draft out the manuscript. EJJ performed the cell culture, ELISA analysis and histopathological examination. UHJ, SHK and STY participated in the design of study. SKJ conceived of the study, and participated in its design. All authors have read and approved the manuscript.

\section{Acknowledgements}

This work was conducted under a grant (M-2007-008) from Daedeok Innopolis R\&BD Program and under a grant (2007-0009I) from the Nuclear R\&D program by Ministry of Education, Science \& Technology of Korea. 


\section{References}

I. Winston JA, Safirstein R: Reduced renal blood flow in early cisplatin-induced acute renal failure in the rat. Am J Physiol 1985, 249:F490-F496.

2. Chirino YI, Hernández-Pando R, Pedraza-Chaverí J: Peroxynitrite decomposition catalyst ameliorates renal damage and protein nitration in cisplatin-induced nephrotoxicity in rats. BMC Pharmacol 2004, 4:20-29.

3. Stewart DJ, Benjamin RS, Luna M, Feun L, Caprioli R, Seifert W, Loo TL: Human tissue distribution of platinum after cis-diamminedichloroplatinum. Cancer Chemother Pharmacol 1982, 1 0:5 I-54.

4. Kim YK, Jung JS, Lee SH, Kim YW: Effects of antioxidants and $\mathrm{Ca}^{2+}$ in cisplatin-induced cell injury in rabbit renal cortical slices. Toxicol Appl Pharmacol 1997, I 46:261-269.

5. Somani SM, Husain K, Whitworth C: Dose-dependent protection by lipoic acid against cisplatin induced nephrotoxicity in rats; Antioxidant defense system. Pharmacol Toxicol 2000, 86:234-24I.

6. Ajith TA, Jose N, Janardhanan KK: Amelioration of cisplatin induced nephrotoxicity in mice by ethyl acetate extract of a polypore fungus, Phellinus rimosus. J Exp Clin Cancer Res 2002 2 I(2):213-2I7.

7. Mora Lde O, Antunes LM, Francescato HD, Bianchi Mde L: The effecs of oral glutamine on cisplatin-induced nephrotoxicity in rats. Pharmacol Res 2003, 47:517-522.

8. Husain K, Morris C, Whitworth C, Trammell GL, Rybak LP, Somani SM: Protection by ebselen against cisplatin-induced nephrotoxicity: Antioxidant system. Mol Cell Biochem 1998, I 78: I27-I33.

9. Ajith TA, Usha S, Nivitha V: Ascorbic acid and $\alpha$-tocopherol protect anticancer drug cisplatin induced nephrotoxicity in mice: a comparative study. Clin Chim Acta 2007, 375( I-2):82-86.

10. Lee CK, Park KK, Lim SS, Park JHY, Chung WY: Effects of the licorice extract against tumor growth and cisplatin-induced toxicity in a mouse xenograft model of colon cancer. Biol Pharm Bull 2007, 30:2191-2195.

II. Engel LW, Straus SE: Development of therapeutics: opportunities within complementary, alternative medicine. Nat Rev Drug Discov 2002, I:229-237.

12. Moriya N, Miwa H, Orita K: Antitumor effect of bacterial lipopolysaccharide (LPS) alone and in combination with lentinan on $\mathrm{MH}-\mathrm{I} 34$ tumors in $\mathrm{C} 3 \mathrm{H} / \mathrm{He}$ mice. Acta Med Okayama 1984, 38(I):49-55.

13. Hamuro J, Takatsuki F, Suga T, Kikuchi T, Suzuki M: Synergistic antimetastatic effects of lentinan and interleukin 2 with preand post-operative treatments. Jpn J Cancer Res 1994, 85: $1288-1297$.

14. Matsuyama H, Mangindaan RE, Yano T: Protective effect of Schizophyllan and Scleroglucan against Streptococus sp. Infection in Yellow Tail (Seriola quinqueradiata). Aquaculture 1992, | 0 |:97-203.

15. Matsuoka H, Yano K, Seo Y, Saito T, Tomoda H, Tsurumoto S: Usefulness of lymphocyte subset change as an indicator for predicting survival time and effectiveness of treatment with the immunopotentiator Ientinan. Anticancer Res 1995 , | 5:229|-2296.

16. Kim KH, Lee YS, Jung IS, Park SY, Chung HY, Lee IR, Yun YS: Acidic polysaccaride fromPanax ginseng, Ginsan, induces ThI cell and macrophge cytokines and generates LAK cells in synergy with rIL-2. Planta Medica 1998, 64: I I0-II5.

17. Ooi VE, Liu F: Immunomodulation and anti-cancer activity of polysaccharide-protein complexes. Curr Med Chem 2000, 7:715-729.

18. Song JY, Han SK, Son EH, Pyo SN, Yun YS, Yi SY: Induction of secretory and tumoricidal activities in peritoneal macrophages by ginsan. Int Immunopharmacol 2002, 2:857-865.

19. Zaidman BZ, Yassin M, Mahajna J, Wasser SP: Medicinal mushroom modulators of molecular targets as cancer therapeutics. Appl Microbiol Biotechnol 2005, 67:453-468.

20. Park HR, Kim SH, Yee ST, Byun MW, Jo SK: Effect of a herb mixture (HIM-I) on the protection of the hematopoieticimmune system and self-renewal tissues against radiation damage. J Korean Soc Food Sci Nutr 2005, 34:605-6I 2.

21. Jo SK, Park HR, Jung UH, Oh H, Kim SH, Yee ST: Protective effect of a herbal preparation (HemoHIM) on the self-renewal tis- sues and immune system against $\gamma$-irradiation. J Korean Soc Food Sci Nutr 2005, 34:805-8I3

22. Kedar E, Klein E: Cancer immunotherapy: are the results discouraging? Can they be improved? Adv Cancer Res 1992, 59:245-322.

23. Hanson HL, Donermeyer DL, Ikeda H, White JM, Shankaran V, Old LJ, Shiku H, Schreiber RD, Alen PM: Eradication of established tumors by CD8+ $\mathrm{T}$ cell adoptive immunotherapy. Immunity 2000, 13:265-276.

24. Seder RA, Gazzinelli R, Sher A, Paul WE: Interleukin $\mathbf{2}$ acts directly on CD4+ T cells to enhance priming for interferon $\gamma$ production and diminishes interleukin 4 inhibition of such priming. Proc Natl Acad Sci USA 1993, 90:10188-10192.

25. Yoshida A, Koide $Y$, Uchijima M, Yoshida TO: IFN- $\gamma$ induces IL- 12 mRNA expression by a murine macrophage cell line, $\mathbf{J 7 4}$ Biochem Biophys Res Commun 1994, I 98:857-86I

26. Park HR, Jo SK, Paik SG: Factors effecting the Th2-like immune response after gamma-irradiation: low production of IL- I 2 heterodimer in antigen-presening cells and small expression of the IL- $\mathbf{2}$ receptor in T cells. Int J Radiat Biol 2005, 8 I:22 I-23 I.

27. Dijt FJ, Fichtinger-Schepman AM, Berends F, Reedijk J: Formation and repair of cisplatin-induced adducts to DNA in cultured normal and repair-deficient human fibroblasts. Cancer Res 1988, 48:6058-6062.

28. Di Santo JP: Natural killer cell developmental pathways: a question of balance. Annu Rev Immunol 2006, 24:257-286.

29. Boogaard PJ, Lempers EL, Mulder GJ, Meerman JHN: 4-methylthiobenzoic acid reduces cisplatin nephrotoxicity in rats without compromising anti-tumor activity. Biochem Pharmacol |991, 4 I: 1997-2003.

30. Ravi RS, Somini SM, Rybak LP: Mechanism of cisplatin ototoxicity. Antioxidant system. Pharmacol Toxicol 1995, 76:386-394.

3I. Park HR, Jo SK, Jung UH, Yee ST: Restoration of the immune functions in aged mice by supplementation with a new herbal composition, HemoHIM. Phytother Res 2008, 22(I):36-42.

32. Park HR, Jo SK, Jung UH, Kim SH, Yee ST: Immunomodulatory effect of a new herbal preparation (HemoHIM) in cyclophosphamide-treated mice. J Food Sci Nutr 2006, I I:54-60.

33. Herberman RB: Cancer immunotherapy with natural killer cells. Seminars in Oncology 2002, 29:27-30.

34. Trinchieri G: Biology of natural killer cells. Adv Immunol 1989 47:187-376.

35. Vivier E, Tomasello E, Baratin M, Walzer T, Ugolini S: Functions of natural killer cells. Nat Immunol 2008, 9:503-5I 0.

36. Boehm W, Thoma S, Leithauser F, Moller P, Schirmbeck R, Reimann J: T cell-mediated, IFN- $\gamma$-facilitated rejection of murine B I 6 melanomas. I Immunol 1998, I 61:897-908.

37. Barth RJ Jr, Mule JJ, Spiess PJ, Rosenberg SA: Interferon $\gamma$ and tumor necrosis factor have a role in tumor regressions mediated by murine CD8 tumor-infiltrating lymphocytes. J Exp Med I99|, I 73:647-658.

38. Ogasawara M, Rosenberg SA: Enhanced expression of HLA molecules and stimulation of autologous human tumor infilterating lymphocytes following transduction of melanoma cells with $\gamma$-interferon genes. Cancer Res 1993, 53:356I-3568.

39. Kaplan DH, Shankaran V, Dighe AS, Stockert E, Auguet M, Old LJ, Schreiber RD: Demonstration of an interferon- $\gamma$-dependent tumor surveillance system in immunocompetent mice. Proc Natl Acad Sci USA 1998, 95:7556-756I.

40. Boehm U, Klamp T, Groot JC, howard JC: Cellular responses to Interferon- $\gamma$. Annu Rev Immunol I 987, I 5:749-795.

4I. Shankaran V, Ikeda H, Bruce AT, White JM, Swanson PE, Old LJ, Schreiber RD: IFN gamma and lymphocytes prevent primary tumour development and shape tumour immunogenicity. Nature 2001, 410: I 107-IIIII.

42. Cregan ET, Ahmann DL, Long HJ, Frytak S, Sherwin SA, Chan MN Phase II study of recombinant interferon-gamma in patients with disseminated malignant melanoma. Cancer Treat Rep | 987, 7|:843-844.

43. Aulitzky W, Gastl G, Aulitzky WL, Hewrold M, Kemmler J, Mull B, Frick J, Huber C: Successful treatment of metastatic renal cell carcinoma with a biologically active dose of recombinant interferon- $\gamma$. J Clin Oncol 1989, 7:1875-I89I.

44. Naglieri E, Gebbia V, Durini E, Lelli G, Abbate I, Selvaggi FP, Di Tonno P, Colucci G: Standard interleukin-2 (IL-2) and interferon- 
alpha immunotherapy versus an IL-2 and 4-epirubicin immunochemotherapeutic association in metastatic renal cell carcinoma. Anticancer Res 1998, I8(3B):202I-2026.

45. Ridolfi R, Flamini E, Riccobon A, De Paola F, Maltoni R, Gardini A Ridolfi L, Medri L, Poletti G, Amadori D: Adjuvant adoptive immunotherapy with tumor-infiltrating lymphocytes and modulated doses of interleukin-2 in 22-patiens with melanoma, colorectal and renal cancer, after radical metastasectomy, and in 12 advanced patients. Cancer Immunol Immunother 1998, 46: 185-193.

\section{Pre-publication history}

The pre-publication history for this paper can be accessed here:

http://www.biomedcentral.com/1471-2407/9/85/prepub

Publish with Bio Med Central and every scientist can read your work free of charge

"BioMed Central will be the most significant development for disseminating the results of biomedical research in our lifetime. "

Sir Paul Nurse, Cancer Research UK

Your research papers will be:

- available free of charge to the entire biomedical community

- peer reviewed and published immediately upon acceptance

- cited in PubMed and archived on PubMed Central

- yours - you keep the copyright 